\title{
Big heart
}

\author{
Yehia Saleh, ${ }^{1,2}$ Abdallah Almaghraby, ${ }^{2}$ Mohamed Seleem, ${ }^{2}$ Basma Hammad ${ }^{2}$
}

'Department of Internal Medicine, Michigan State University, East Lansing, Michigan, USA

${ }^{2}$ Department of Cardiology, Faculty of Medicine, Alexandria University, Alexandria, Egypt

\section{Correspondence to} Dr Yehia Saleh, yehia.saleh@hc.msu.edu

Accepted 30 May 2018

\section{DESCRIPTION}

A 66-year-old female patient with a history of persistent atrial fibrillation and severe mitral stenosis secondary to rheumatic heart disease for which she underwent mitral valve replacement 25 years ago presented with progression of her baseline dyspnoea. On presentation, she had stable vital signs; neck examination revealed bilateral congested neck veins with prominent systolic venous pulsations. Chest and heart auscultation revealed a wellheard mechanical click, a pansystolic murmur heard over the tricuspid area and diminished air entry over the right lung base.

ECG revealed atrial fibrillation. Laboratory work-up showed that she was adequately anticoagulated but otherwise unremarkable; chest X-ray showed significant cardiomegaly, tracheal shift to the right and obliteration of the right basal lung field (figure 1).

Echocardiography showed a preserved systolic function, well-functioning mitral valve prosthesis, severe tricuspid regurgitation, severe pulmonary hypertension and a giant left atrium (GLA) measuring about $160 \mathrm{~mm}$ with an estimated volume of 2.5 litres (figures 2 and 3). Subsequently, CT revealed that the left atrium is hugely dilated occupying a considerable amount of the hemithorax measuring $200 \times 155 \times 182 \mathrm{~mm}$ and causing subtotal collapse of the right lower lobe (figure 4).

Management was directed to treat heart failure; unfortunately, her condition deteriorated leading to respiratory failure requiring mechanical ventilation. Eventually, comfort care measure was applied and the patient passed away.

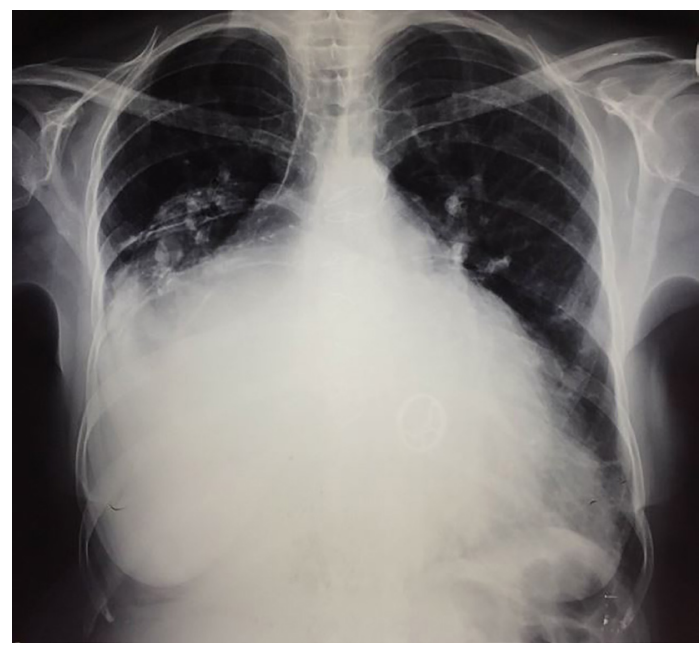

Figure 1 Chest X-ray showing significant cardiomegaly, tracheal shift to the right and obliteration of the right basal lung field.

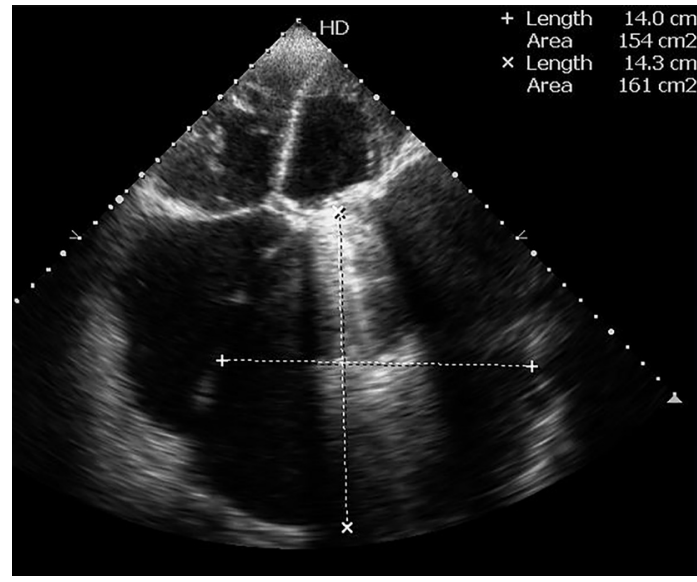

Figure 2 Echocardiogram in apical four-chamber view showing an enlarged left atrium measuring $140 \times 143 \mathrm{~mm}$.

GLA is predominantly caused by neglected rheumatic mitral disease; however, other conditions such as persistent atrial fibrillation and left ventricular failure can lead to left atrial dilation but to a lesser extent. ${ }^{1}$ Our patient had severe mitral stenosis and atrial fibrillation for years prior to having mitral valve replacement; at that time, she already had a giant left atrium $(13 \mathrm{~cm}$ on echocardiogram). Although the valve was replaced, the left atrium continued to dilate over the past 25 years secondary to atrial fibrillation.

GLA was historically defined as a left atrium touching the lateral chest wall in chest X-ray; however, after the introduction of echocardiography, several authors have redefined it to greater than $6 \mathrm{~cm}$. Ates et al reported the largest left atrium shown by echocardiography with a diameter of $187 \mathrm{~mm}$.

When the left atrium enlarges, it moves to the right occupying the right hemithorax. Differential diagnosis of the right heart border touching the right thoracic wall includes GLA, right atrial tumours, congenital abnormalities, tumours of the mediastinum, right pleural effusion or even pericardial effusion. Hence, echocardiography is mandatory prior to any invasive procedures such as pericardiocentesis or pleurocentesis. ${ }^{2}$

Several complications may arise from compression of the surrounding structures such as haemodynamic compromise resulting from compression of the left ventricular wall, respiratory disturbance resulting from compression of the left main bronchus or right lung collapse, in addition to compression of the oesophagus leading to dysphagia. Rarely, it may compress the left laryngeal nerve leading to hoarseness of voice. ${ }^{3}$

There are no guidelines regarding intervention on lone giant left atrium without significant mitral 


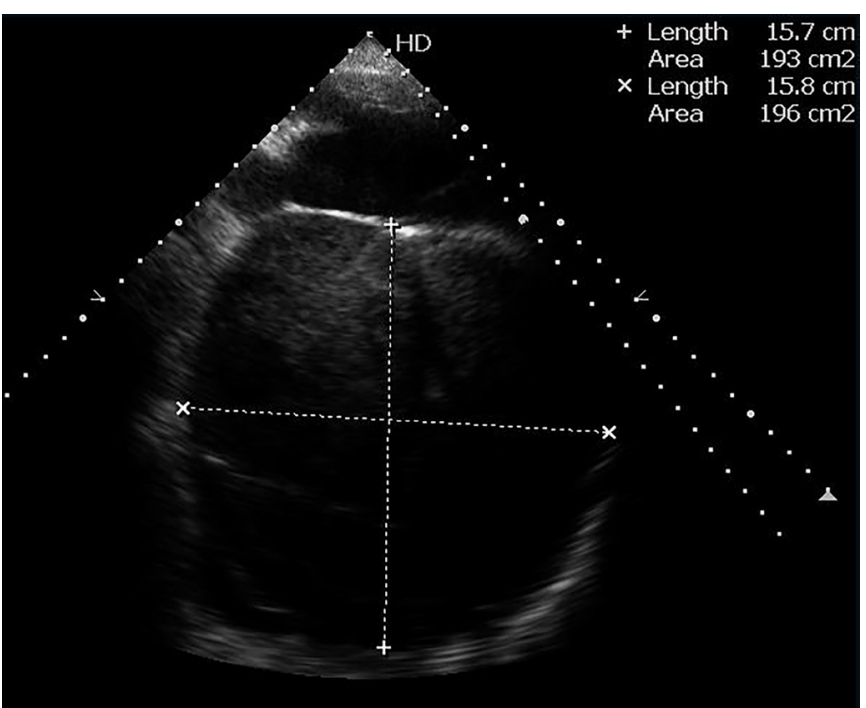

Figure 3 Echocardiogram atypical view showing an enlarged left atrium measuring $157 \times 158 \mathrm{~mm}$.

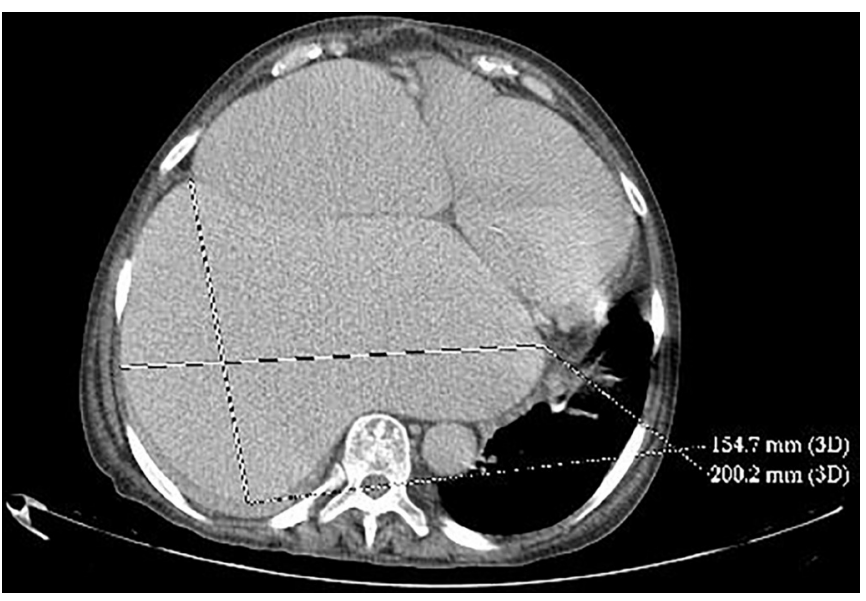

Figure $4 \mathrm{CT}$ of the chest showing a giant left atrium measuring $200 \times 154 \mathrm{~mm}$. valve affection; however, intervention is usually limited to significant compressive symptoms. In case of GLA in addition to significant mitral affection, most surgeons fix the mitral valve only unless there are compressive symptoms, presence of a thrombus in the left atrium or history of thromboembolism. ${ }^{3}$ In our case, the surgical option was debatable as there were no frank compression symptoms; at the same time, the patient refused any surgical intervention.

Giant left atrium is a rare disorder that usually results from rheumatic mitral valve disease. However, due to high rates of immigration, more patients with complex rheumatic heart disease are presenting nowadays to the western world.

Learning points

- Giant left atrium is a rare disorder that usually results from rheumatic mitral valve disease.

- Compression of the surrounding structures such as left ventricular wall, main bronchi, lungs, oesophagus and left laryngeal nerve is the main concern.

- Surgery is only warranted to relieve compressive symptoms.

Contributors YS worked on the manuscript and was involved in the patient care. $\mathrm{AA}$ assisted with writing the manuscript. MS and $\mathrm{BH}$ were involved in the patient care, and they revised the manuscript and provided the images.

Funding The authors have not declared a specific grant for this research from any funding agency in the public, commercial or not-for-profit sectors.

Competing interests None declared.

Patient consent Next of kin consent obtained.

Provenance and peer review Not commissioned; externally peer reviewed. (c) BMJ Publishing Group Ltd (unless otherwise stated in the text of the article) 2018. All rights reserved. No commercial use is permitted unless otherwise expressly granted.

\section{REFERENCES}

1 Ates M, Sensoz Y, Abay G, et al. Giant left atrium with rheumatic mitral stenosis. Tex Heart Inst J 2006;33:389-91.

2 Hurst JW. Memories of patients with a giant left atrium. Circulation 2001;104:2630-1. 3 El Maghraby A, Hajar R. Giant left atrium: a review. Heart Views 2012;13:46-52.

Copyright 2018 BMJ Publishing Group. All rights reserved. For permission to reuse any of this content visit http://group.bmj.com/group/rights-licensing/permissions.

BMJ Case Report Fellows may re-use this article for personal use and teaching without any further permission.

Become a Fellow of BMJ Case Reports today and you can:

- Submit as many cases as you like

- Enjoy fast sympathetic peer review and rapid publication of accepted articles

- Access all the published articles

- Re-use any of the published material for personal use and teaching without further permission

For information on Institutional Fellowships contact consortiasales@bmjgroup.com

Visit casereports.bmj.com for more articles like this and to become a Fellow 